\title{
AN ENGINEERING APPROACH TO AN INTEGRATED VALUE PROPOSITION DESIGN FRAMEWORK
}

\author{
C. van der Merwe ${ }^{1 \dagger}$, A. van Rensburg ${ }^{2}$ \& C.S.L. Schutte ${ }^{3 *}$ \\ ${ }^{1,2,3}$ Department of Industrial Engineering \\ Stellenbosch University, South Africa \\ ${ }^{2}$ antonie@sun.ac.za, ${ }^{3}$ corne@sun.ac.za
}

\begin{abstract}
Numerous problems with product quality and time-to-market launches can be traced back to how the product lifecycle process is managed within the organisation. This article provides insight into how an integrated value proposition design framework shifts product lifecycle management from a product-centric view to a customer-centric view, through the use of good engineering practices as found in the systems engineering discipline. Combining this with methods and tools such as the Refined Kano model, Blue Ocean strategy, and the Generalised Bass model enables the organisation to enhance product and service quality while reducing the time-to-market for new value proposition launches.
\end{abstract}

\section{OPSOMMING}

Die bestuur van produkte se lewensiklusse kan vele probleme veroorsaak wat gepaard gaan met die kwaliteit van produkte en die verlengde tydperk om produkte in ' $n$ mark vry te stel. Hierdie artikel stel 'n geïntegreerde waarde-stelling raamwerk voor wat die fokus van die produk lewensiklus bestuursproses skuif van 'n produk-gesentreerde fokus na 'n kliëntgesentreerde fokus, deur gebruik te maak van goeie ingenieurs praktyke soos gevind in die stelselsingenieurswese dissipline. Die raamwerk kombineer stelselingenieurswese praktyke met metodes soos die 'Refined Kano' model, die 'Blue Ocean' strategie en die 'Generalised Bass' model. Daardeur stel die raamwerk die organisasie in staat om hulle produkte en dienste se kwaliteit te verbeter, en terselfde tyd die produk vrystellings tydperk te verkort.

$\dagger \quad$ The author was enrolled for an M Eng (Industrial)(Research) degree in the Department of Industrial Engineering, Stellenbosch University

* Corresponding author 
The custom of value exchange between two or more parties is an age-old tradition. Today organisations spend hours preparing and strategising different value offerings in order to offer benefits to the marketplace to secure future income streams. In an ever-competing world where breakthrough innovations are harder to obtain, and where it is even more difficult to differentiate product and service offerings from those of competitors, organisations have to start competing on management practices [22]. This paper is based on the principle that added economic growth can be achieved by applying formal practices during the value proposition design stages in the product lifecycle management, as borrowed from the engineering, marketing, project management, and financial disciplines.

A product is a value offering to a customer that consists of a combination of tangible and/or intangible components. Product lifecycle management (PLM) entails the process of managing the entire lifecycle of the product from initiation to product demolition and replacement. It forms a knowledge management process inside the organisation that integrates resources, stakeholders, data, and business processes in order to provide an information outline of the product. Traditionally, PLM is used as a business strategy to establish a product-centric environment through which the organisation effectively continually delivers products to its customer base over time to sustain organisational growth.

This article introduces a different approach to PLM by shifting the predominantly productcentric focus to that of customer-centricity. This is done by defining an engineering framework of processes, principles, and methods that introduces key concepts, such as multifunctional team integration and business process parallelisation, into the PLM. The aim of this framework is to reduce variation in process schedules and to align design specifications around the voice of the customer, while maintaining flexibility among stakeholders in the process, with the intended effect of reducing time-to-market and increasing product quality.

The article is structured as follows. First, a brief background is presented on the research problem and the environment in which the integrated value proposition design framework was formulated. Then the best practice methods are discussed and placed in the context of the proposed approach to follow in an integrated value proposition design framework. The rationale for the framework is presented, followed by the framework structure and the implementation strategy of the framework. The article concludes with a summary of the framework and the potential benefits of its application in the PLM of the organisation.

\section{BACKGROUND}

The goal of PLM is to provide and capture accurate knowledge that enables product development and in-life product maintenance, and guides stakeholders to make accurate and informed decisions. PLM is a complex effort that requires systematic and dynamic planning, coupled with a strong leadership focus, in order to be successful.

In order to describe the context within which the value proposition design framework was developed, some key definitions and concepts are provided from the existing literature. The literature review, which focuses on the central themes in product management, compares product-centric views with customer-centric views, and unpacks how customercentric views provide opportunities to significantly improve the key performance measurements of PLM.

\subsection{Key definitions and concepts}

Central to the value proposition framework are the concepts of 'value proposition' and 'customer-centricity'. A value proposition is the encapsulation of the expectation of the customer to experience value through the promises of the organisation. Being able to create successful value propositions offers significant strategic advantages to an 
organisation. The concept of a value proposition can be applied to an entire organisation, business unit, product, or service, as long as the process of value exchange can be defined between a 'supplier' and a 'customer' [4]. 'Customer value propositions' is one of the most frequently used terms in marketing. One of the major shortcomings of customer value propositions is that marketing managers use them as a marketing scheme or gratification method, but rarely take ownership of the value propositions [2]. For large and complex organisations, the lack of integration between multiple stakeholders in the design of customer value propositions will most likely have a direct impact on the success of the innovation. With a customer-centric focus, organisational strategies are combined with consumer needs to generate profit by maximising the lifetime value of the customer [3].

\subsection{Central problems in managing products}

Product failures can frequently be traced back to poor management practices. Numerous research studies have been conducted to identify universal problems in PLM. Van de Ven [24] identifies four universal problems associated with the management of the product development lifecycle. The first problem is that of managing humans, especially in a large and successful organisation. Generally, organisations are focused more on protecting their existing products and services than on innovating new ideas.

The second problem is the challenge of transforming an idea into a product as a collective achievement. It only takes one person to propose an idea; but for the idea to be invented and implemented, it requires the co-operation of various groups of individuals. It is often found that a promising idea will not be invented successfully due to a lack of energy and commitment among multifunctional groups.

The third problem involves the structural problem of holistically managing multiple functions, resources, and disciplines. Individuals involved in the innovation development process can get so involved in their own functional responsibilities that they can easily lose sight of the process as a whole.

The fourth problem is a lack of leadership. The development of an innovation has to adapt to current organisational structures and practices. It is often found that the existing management strategies are very rigid, not allowing flexibility to adapt to the current innovation development's requirements. There is a lack of strategic leadership to transform the existing management practices to optimise the innovation's go-to-market cycle strategy [24].

The central problems of innovation management, which are universal and apply to any industry and organisation, are divided into four main categories: human, process, structure, and strategy.

Kessler et al. [16] define the 'vasa syndrome', a term known in marketing and management that refers to project failure due to insufficient communication. In essence, it refers to the necessity of identifying the customer and addressing the customer need in the market. This can be attributable to the fact that there are seven potential problems that an organisation faces during the new product development stage in the PLM. Some of these potential problems include a deficiency in learning ability, a poor knowledge and information feedback system, communication obstructions, and most prominently, the inability to recall insights from previous products. To counter the vasa syndrome, an organisation needs to emphasise the importance of the knowledge gained from previous experiences, and the importance of sharing this knowledge and promoting the information systems that need to be in place to overcome communication barriers and poor organisational retention capability [1].

\subsection{Product-centric vs customer-centric}

A product-centric organisation's aim is to introduce leading products into the market and to make use of their internal ability to deliver successful high-tech, cutting-edge products. Organisational strategies are defined according to the product and supporting key 
performance indicators, such as the annual product revenue or the number of new products realised per year. In contrast, a customer-centric organisation focuses on delivering the best solution to the customer by designing products and services that are customised for specific customer segment needs. Typically, such organisations will have visible key performance indicators, such as customer lifetime value and customer satisfaction [21].

Numerous problems are associated with product-centric management strategies. The most common are poor customer experience from a customer perspective, and inflexible management practices experienced during the PLM. In the end the success of the product is often considered before the need of the customer; but even if a product performs functionally according to its specifications, it will be unsuccessful in the market place if it does not address a real customer need.

\section{BEST PRACTICE METHODS AND TOOLS}

The framework is a result of studying and applying a number of best practice methods and tools, including customer segmentation, customer lifetime value, value analysis, the Refined Kano's model, the Blue Ocean strategy, customer experience, the Generalised Bass model, quality function deployment, and the Monte Carlo simulation. This section provides an overview of each of these best practice methods as background to understanding the integrated value proposition design framework.

\subsection{Customer concepts}

In order to formulate the framework from a marketing strategy perspective, a number of customer concepts are used, such as customer experience, customer life time value, customer segmentation, and customer value.

Customer experience involves the emotions of a customer while engaging with a product or service. Customer experience can be enhanced by designing a product or service to promote customer interaction [15]. This can be done by describing the customer experience in terms of a customer journey map and, within the map, managing the touch points with the customer. The customer journey $[7,18]$ captures the desired experience that the customer should have while engaging with the organisation, the product, or service throughout the 'cradle-to-grave' lifecycle of the product or service. 'Customer touch points' refers to any point of contact where the customer and the organisation meet to exchange benefits [8].

Customer lifetime value (CLV) is a prediction of the net profit worth of a customer across the period of customer engagement. Various researchers have conducted studies on how organisations should manage customers as investments across their lifetimes [12]. The basic principle of this is that an organisation should not overspend on a customer who does not generate a sufficient amount of profit, but invest relevant resources to a specific customer value band. CLV is calculated on an individual customer level. It incorporates the possibility that customers can leave the organisation and move over to competitors, and the cost of acquiring the customer. The CLV per customer is calculated as follows [12]:

$$
C L V=\sum_{t=0}^{T} \frac{[p(t)-c(t)] r(t)}{(1+t)^{t}}-A C
$$

where:

$p(t)$ is the price a customer pays at time $t$

$c(t)$ is the direct cost of the product or service at time $t$

$i$ is the discount rate at time $t$

$r(t)$ is the probability that a customer will return to the organisation at time $t$

$A C$ is the acquisition cost of the customer

$T$ is the lifetime period of customer engagement 
Customer segmentation is the practice of dividing customers into different groups of individuals who have similar needs. These target groups are alike in specific ways, such as gender, age, interests, spending behaviour, and demographics. The manner in which this process is followed varies from organisation to organisation. For example, traditional segmentation will group customers according to their demographic and psychological information. In this study, the practice of value band segmentation was followed, grouping customers into segmentations according to the amount of annual revenue generated per customer segment [10].

Customer value is the trade-off between what a customer perceives to give in order to obtain the returned value from a product or service. Customer value depends on how much a product or service contributes to fulfilling customer needs, and how the product or service differs from competing products or services. Value can be added to a customer in four value categories:

- 'Economic value' [13] is the financial benefit a customer obtains when using a product or service.

- 'Functional value' [13] is the practical benefits a customer receives from the performance or the features of the product or service.

- 'Psychological value' [13] is the benefits associated with the intangible values of the product or service, such as brand names.

- 'Creative value' [25] is the value added to the customer when using the breakthrough idea for the first time.

Within the marketing strategy of the organisation, different marketing objectives can be defined, based on how customers are going to contribute to the sales revenue of the organisation within the context of the customer segmentation and marketing revenue models. In the framework definition, marketing objectives have been identified as the ability to retain the customer (customer retention), acquire the customer (customer acquisition), or grow the customer profitability (customer growth) within particular segments across the lifetime value.

\subsection{The Refined Kano's model}

Kano's model is a best practice quality measurement tool used in product and service development processes to classify product and service attributes according to how customers perceive them [20]. The model classifies product attributes into five categories: must-be attributes, one-dimensional attributes, attractive attributes, indifferent attributes, and reverse attributes. Yang [25] improved Kano's model and developed a Refined Kano's model to take into account a customer's perception of the degree of importance of a quality attribute (Figure 1).

A one-dimensional quality attribute is an attribute that represents a linear relationship between a customer's perception that the quality attribute will satisfy their need and the quality attribute's ability to fulfil it. Better fulfilment in one-dimensional attributes helps to improve customer satisfaction, and contrariwise. One-dimensional attributes with a high importance are 'high value-added' quality attributes. These attributes should be maximised because to a great extent they generate customer satisfaction. One-dimensional attributes with a low importance are 'low value-added' quality attributes. Low value-added quality attributes do not contribute to customer satisfaction to such a great degree; organisations cannot avoid these attributes, however, because their absence will cause customer dissatisfaction.

'Must-be' quality attributes are those that result in absolute customer dissatisfaction when absent from the innovation, but that, when present, do not contribute to customer satisfaction. A customer expects to find must-be quality attributes present in a product. Must-be attributes with a high importance become 'critical' quality attributes. Critical quality attributes are vital in an innovation for it to function successfully. Must-be 
attributes with a low importance are 'necessary' quality attributes. Organisations should meet these requirements on a desired level in order to avoid customer dissatisfaction.

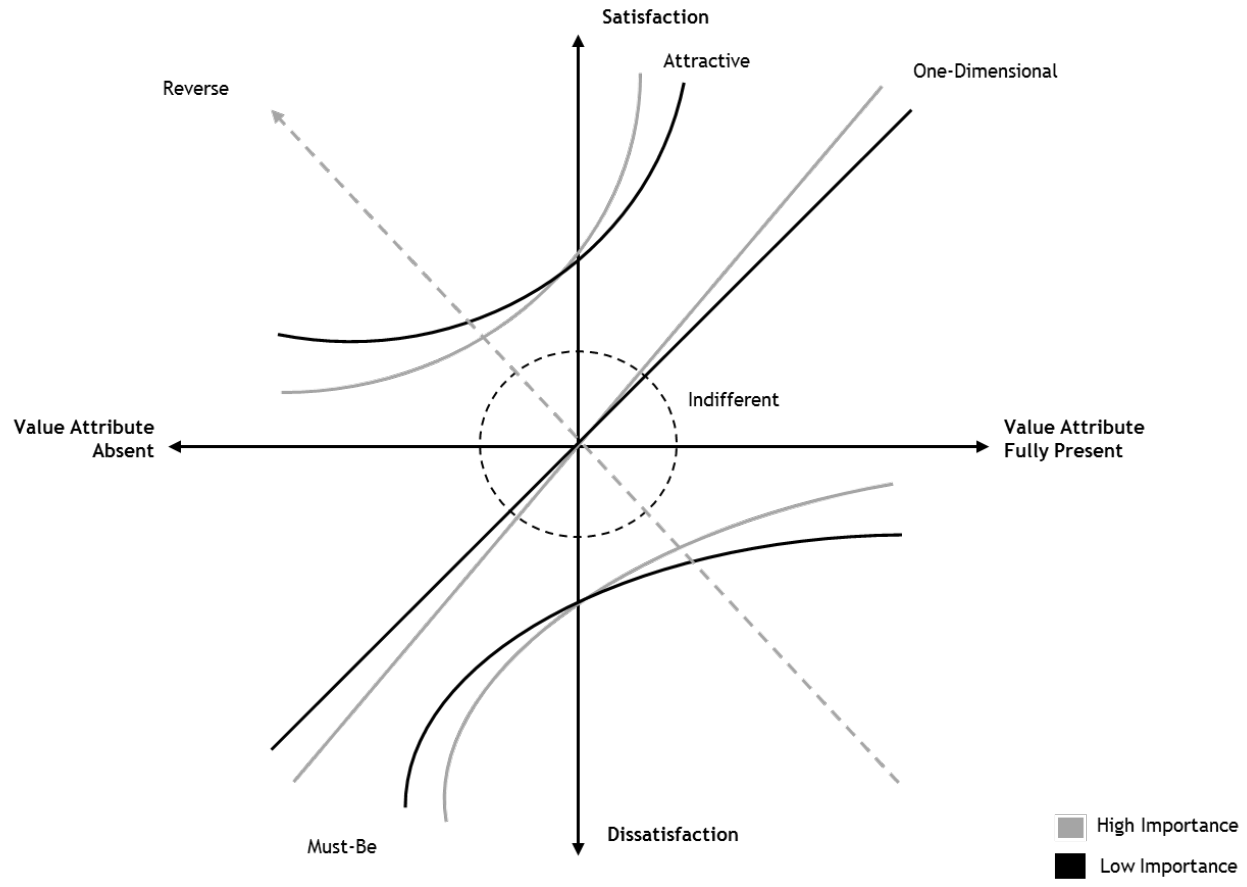

Figure 1: The Refined Kano's model [26]

'Indifferent' quality attributes contribute to neither customer satisfaction nor customer dissatisfaction. 'Reverse' quality attributes result in absolute customer dissatisfaction when present and customer satisfaction when absent. Indifferent attributes with a high importance are 'potential' quality attributes. These have the potential to turn into attractive quality attributes. Indifferent attributes with a low importance are 'care-free' quality attributes. Care-free quality attributes should be completely avoided.

'Attractive' quality attributes lead to the greatest customer satisfaction when present, but customers do not expect to find an attractive quality attribute present in a product. The result is no customer dissatisfaction when absent, but extreme customer satisfaction when present. Attractive attributes with a high importance become 'highly attractive' quality attributes. These are an organisation's strategic offerings because, in essence, they attract new customers. Attractive attributes with a low importance are 'low attractive' quality attributes. Low attractive quality attributes can be removed in cost vs quality trade-offs.

\subsection{The Blue Ocean strategy}

The Blue Ocean strategy is a strategic toolset used to exemplify a product or service in a current market. It is known as the 'value innovation' because it differentiates an organisation in such a way that it transforms the market into a new environment, propelling the organisation forward as an industry leader. The Blue Ocean strategy offers four possible strategic actions for the organisation [17]:

1. Create: to define new offerings that the industry has never seen before;

2. Raise: to change existing offerings well beyond the industry norm;

3. Reduce: to downgrade existing offerings well below the industry norm; and

4. Eliminate: to eliminate offerings that the industry takes for granted. 


\subsection{Quality Function Deployment}

Quality function deployment (QFD) is a very efficient communication and decision-making tool that can be used in any decision-making situation. It takes a subjective attribute and converts it into an objective attribute that can be measured and quantified. Within the QFD, the 'house of quality' enables cross-functional team communication through analytical means to ensure accurate and quantifiable results [14].

\subsection{The Generalised Bass model}

The Bass model is a diffusion model that predicts how a product adapts in a market. It can accurately forecast the lifecycle sales pattern for products under two conditions: either the product has been introduced into the market recently and sales have been observed for a certain period of time; or the new product is similar to an existing product with known sales figures [6]. The Bass model determines the probability that a consumer will adapt to a product, given that the consumer has not yet adapted to it. The Bass model describes the process or lifecycle of how a product adapts in a market as an interaction between consumers and potential consumers. The timing of a consumer's initial purchase of a product is dependent on the number of previous buyers. The Bass model presents a rationale of individuals behaving in an innovative and imitative manner.

The Bass model equation is:

where

$$
n(t)=p m+(q-p) N(t-1)-\frac{q}{m}(N(t-1))^{2}
$$

$m$ represents the total number of initial buyers over the period of interest,

$p$ is the coefficient of innovation,

$q$ is the coefficient of imitation,

$n(t)$ is the number of initial buyers at time period $t$,

$N(t)$ is the cumulative number of initial buyers at time period $t$.

Bass et al. [5] developed a Generalised Bass model that incorporates the effect of a difference in a product's price and advertising spend on the likelihood of adoption at time $T$. This is done by adding a multiplicative factor $Z(t)$ to the original model.

$Z(t)$ is:

$$
n(t)=\left[p m+(q-p) N(t-1)-\frac{q}{m}(N(t-1))^{2}\right] Z(t)
$$

$$
Z(t)=1+\alpha \frac{P(t)-P(t-1)}{P(t-1)}+\beta \max \left\{0, \frac{A(t)-A(t-1)}{A(t-1)}\right\}
$$

$a$ is the coefficient representing the percentage of increase diffusion speed due to a one per cent decrease in the price of the product, $P(t)$ is the price of the product at time period $t$,

$B$ is the coefficient representing the percentage of increase diffusion speed due to a one per cent increase in advertising spend,

$A(t)$ is the advertising spend at time period $t$.

\subsection{Accounting for risk in the product up-take model: The Monte Carlo simulation}

The Monte Carlo simulation is a method that incorporates sensitivity analysis into equations to account for any uncertainties in a model's parameters [19]. Any parameters in a mathematical model with inherent uncertainty are replaced with a probability distribution function. The results are calculated thousands of times, using a different set of variables from the probability distribution function. A product uptake model combined with a Monte Carlo simulation holds numerous advantages, as it gives a probabilistic result and a graphical explanation of the various scenarios that could result within the forecasted time, and it simplifies sensitivity and correlation analysis. 
As stated in the introduction, the rationale of the framework is to move from a traditional PLM focus, which is product-centric, to a customer-centric focus. This means that the entire lifecycle, from product concept to product attributes, is aligned towards the customer and their needs and wants. In order to gain market and financial benefits from this approach, the framework needs to be able to reduce the time-to-market during the lifecycle and to increase significantly the product and service quality from the perspective of the customer. To do so requires the implementation of a number of practices into the PLM that will address the shortcomings of current PLM processes and deal with organisational complexities.

\subsection{Current PLM process}

Traditionally, PLM is a product-centric process that captures and integrates the data, resources, and processes of the product.

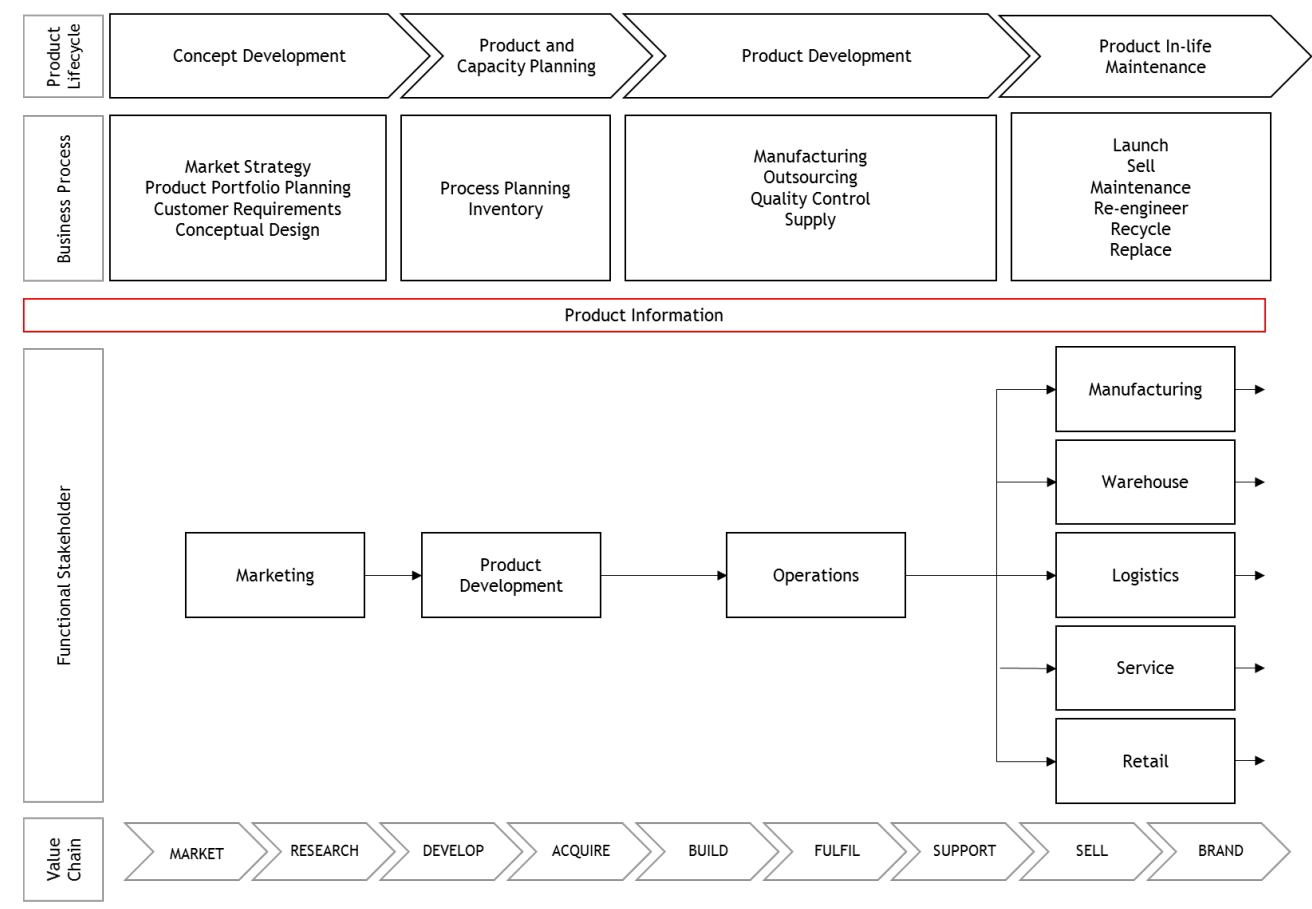

Figure 2: Traditional PLM approach

The PLM process typically follows a serial processing method, which means that stages follow completed stages throughout the product development lifecycle. It is known to make use of multifunctional teams to deliver tasks in sequential intervals [9,11]. Even though most organisations follow a customer-oriented approach to define the concept in the concept development stage, the entire PLM process is mostly product-focused [27].

\subsection{New approach to PLM}

PLM research places emphasis on how products and services should be customer-oriented, together with methods on how to capture those requirements and translate them into design specifications $[25,23]$. Despite this, little research is available on shifting the PLM process from product features towards a customer-centric value proposition focus.

In this new approach to PLM, the integration of multifunctional teams, data, and business process parallelisation enables the PLM cycle to compress time activities together and allow for parallel activities across a good integration and communication model. In this process, the formulation and management of products happen through the design and maintenance 
of the product value propositions according to how customers perceive them, and translate organisational strategies into product value propositions in order to maximise the customer lifetime values.

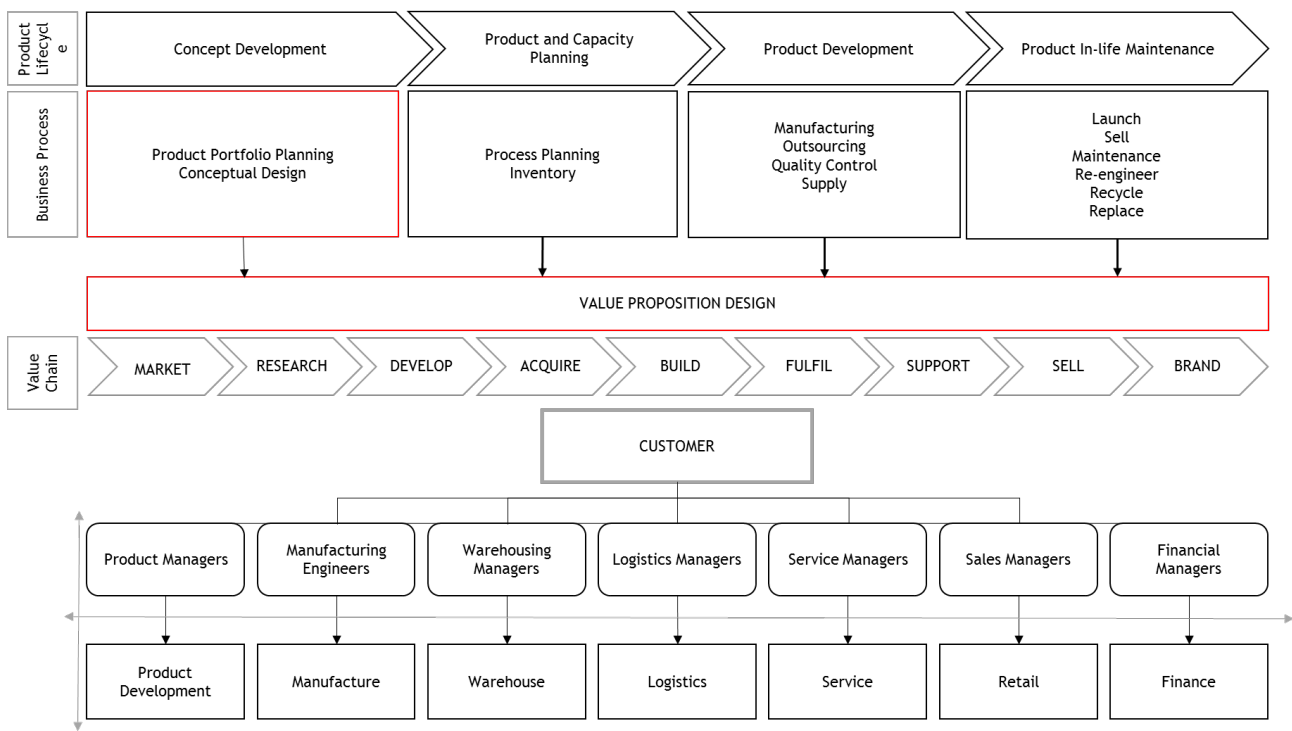

Figure 3: The new approach to PLM

\subsection{Objectives of the integrated value proposition design framework}

The ultimate aim of any product development effort is to launch a successful product in a market, thus generating sufficient profit for the organisation within targeted time frames. A number of key objectives have been defined for the integrated value proposition design framework:

- Use best practices to increase the effectiveness and efficiency of a PLM process;

- Create a deeper understanding of customer requirements, problems, and market opportunities, while tracking customer value creation;

- Integrate large multifunctional team members across various departments;

- Simplify all value proposition design elements on a single A4 page for communication purposes; and

- Support trade-off analysis in the design process by means of a quantitative measurement tool.

The rationale of the integrated value proposition design framework supports the change from product-centricity towards customer-centricity by using six design principles to support a PLM process. The business benefit of this is that customer requirements are tied into the product features through a process that aims to develop and deliver products in a quick time-to-market approach.

\section{THE INTEGRATED VALUE PROPOSITION DESIGN FRAMEWORK}

The integrated value proposition design framework is defined in three parts: the design principles, the process followed in application and implementation of the framework, and the methods and tools used in the framework.

\subsection{Design principles}

Using the framework rationale presented in the previous section, a number of design principles are defined for the framework that guide the application and implementation of the framework in the PLM. 
The first design principle is the 'parallelisation' of work activities. This means that work that can be done in parallel must be done in that way. The second design principle is that of 'backwards scheduling'. This means that the committed product launch date is used as the target date for the project, and all work activities should be scheduled backwards from that date. The third design principle is 'milestones', which define critical stages in the process that captures major events on the critical path, which need to be discussed and/or agreed upon. At these points, the organisation will be able to determine if serious delivery data slippages will occur, and if they have occurred, by how much the project will slip. The fourth design principle is to make use of 'small teams' of the appropriate capabilities. The appropriate team size should not exceed more than seven people.

The fifth design principle is 'simplicity'. For this framework, 'simplicity' means that the complete value proposition design is contained within a one-page design. This enables the team to simplify communication and integration requirements on a strategic and tactical level that has been applied successfully in the course of the business model design [23]. Embedded in this principle is the fact that the core PLM team manages the vertical and horizontal integration specifications according to good systems engineering practices, allowing the small teams to operate in a modular fashion.

The final design principle is to define 'clear metrics' at every stage in the framework to quantify and validate decision-making.

\subsection{The framework process}

The framework process consists of seven steps, as illustrated in Figure 4. The order of the functional tasks in the process aims to support the development and alignment of the customer requirements towards the marketing objectives of the organisation. The process starts with the value proposition strategy (Step 1) - that is, capturing the idea of the value proposition. The verification of the idea into a successful product is clarified and defined by the multifunctional team in this stage, and results in a high level business plan. In Step 2, the core PLM team determine the best applicable customer segmentation model and segments to target with the value proposition model.

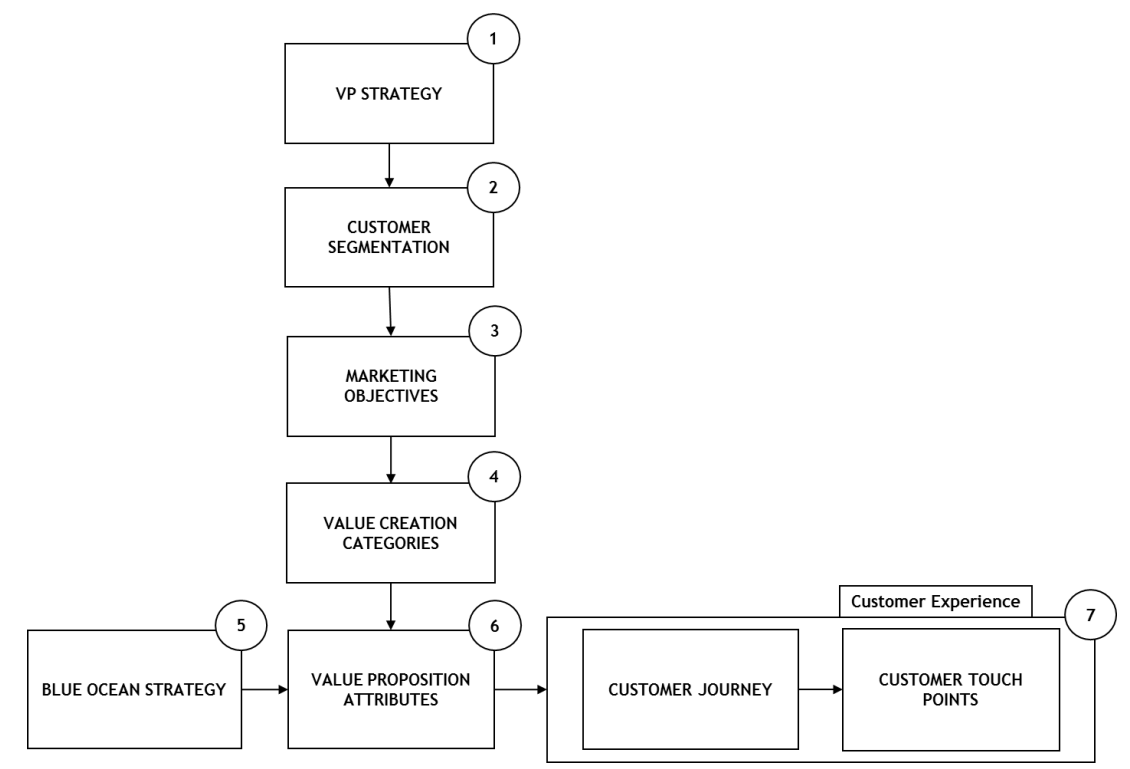

Figure 4: The functional procedure of the integrated value proposition design framework

For Steps 3 to 6 , the value creation model is used to suggest possible actions to enhance customer value from a functional, economic, psychological, or creative view. This model 
links to the Refined Kano's model and the Blue Ocean strategy to identify in which value categories customers will obtain value and through which marketing strategy it will be realised.

The model allows the decision-makers to use a forward and backward analysis to align customer lifetime value through the appropriate strategies of acquisition, retention, and growth to the product quality attributes. The QFD allows the decision-makers to allocate percentages quantitatively to these strategies, which in turn support budget allocation - for example, 60 per cent acquisition-driven, 30 per cent growth-driven, and 10 per cent retention-driven allocations.

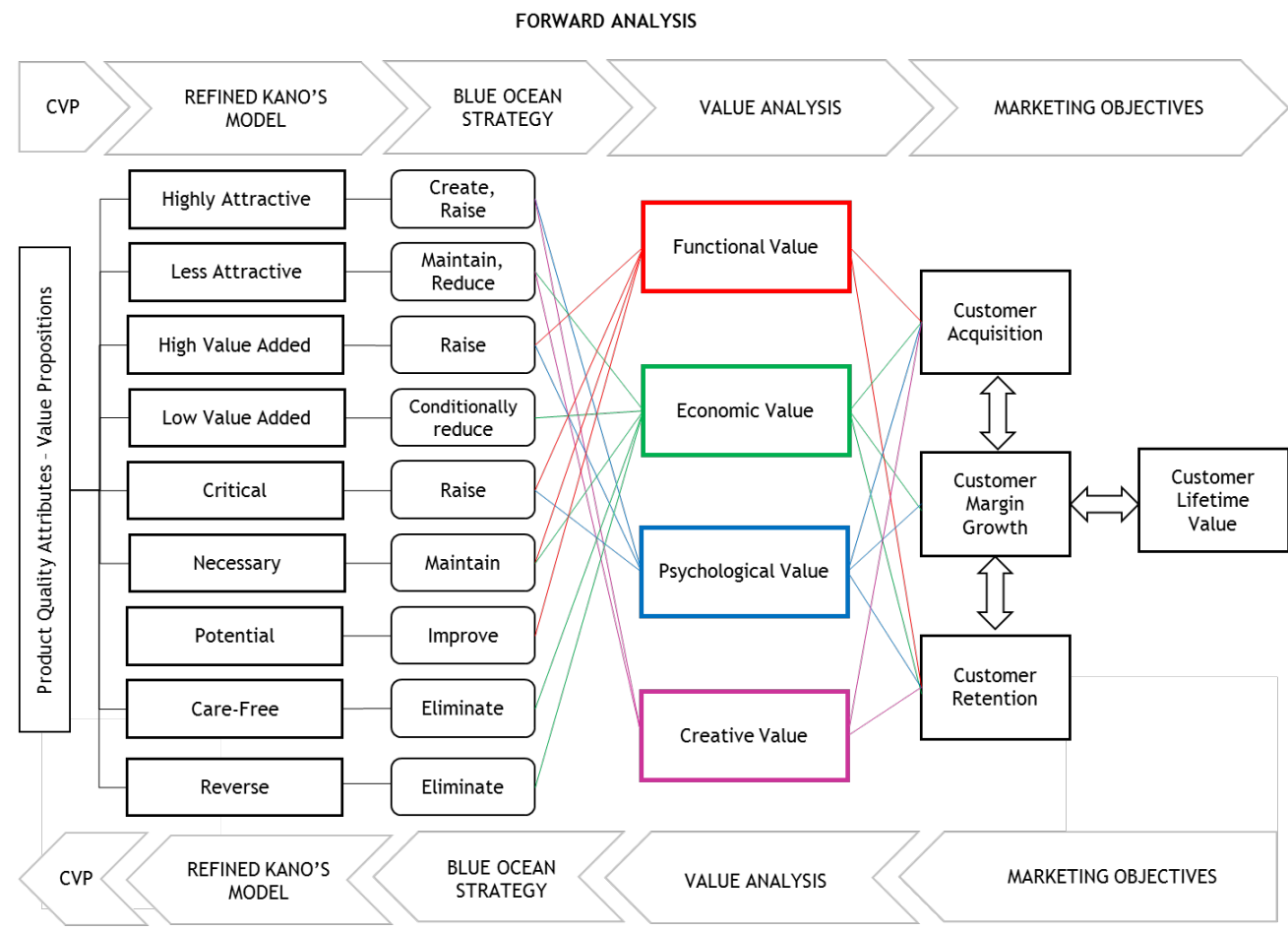

BACKWARD ANALYSIS

Figure 5: Model of value creation [25]

As the calculated customer lifetime value is now allocated to particular marketing objectives, the next step is to quantify and allocate the contribution of value categories. These were allocated in the same way as the allocation of the marketing objectives. Using the QFD, the team can decide quantitatively how a 60 per cent acquisition target can be achieved, for example; that is, 20 per cent functional value, 40 per cent economic value, 20 per cent psychological, and 20 per cent creative value. This allocation of marketing objectives and value categories occurs simultaneously, and the connectors in the model allow the alignment and traceability of these allocation decisions. That is, it becomes clear how the organisation will deliver on a specific value proposition and which marketing strategy it will follow.

Linking the value categories to the product quality attributes requires a combination of the Refined Kano model and the Blue Ocean strategy. The Kano model translates product attributes through a structured process into nine Refined Kano attributes, which the Blue Ocean strategy uses to determine which product strategy should be followed with each Refined Kano attribute. Linking the Blue Ocean strategy with value categories ties the customer lifetime value through the marketing objectives to the value categories, through competitor action strategies to the physical attributes of the value proposition. 
Upon completion of the value proposition attributes, the next step is to map these attributes against the required customer experience vis-a-vis the customer journey and customer touch points. This means that attributes contribute towards the customer journey and customer touch points, and are traceable through the design in a forward and backward manner.

Throughout the value proposition design process, the value propositions should constantly be examined and adjusted according to how the customers perceive and experience the value offerings. The value propositions should also be validated continually to ensure that they will realise the organisation's marketing objectives. The value creation model (Steps 3 to 6) can be repeated forwards and backwards as many times as necessary to ensure that a desired set of value propositions that will realise the marketing objectives are determined.

\subsection{Implementation approach}

The tasks of the integrated value proposition design framework are executed in parallel. The order of the functions in the model is essential to illustrate a complete process of value creation. The critical path of the integrated value proposition design framework consists of a series of identified milestones that need to be completed in a serial manner; however, the multifunctional teams are assigned to complete tasks in parallel between these milestones. The core PLM team, which should not be larger than seven individuals, should be senior representatives in the organisation with sufficient delegation authority to remove obstacles for the different teams. Strong leadership is required in the core PLM team to ensure that targets on the milestones are met through proper project management and problem resolution. The core execution strategy is shown in Figure 6, and all plans should resemble this approach. A formal functional design approach, such as the integrated definition language (KBSI Software, IDEF method, available at http://www.idef.com/) structure, is proposed here.

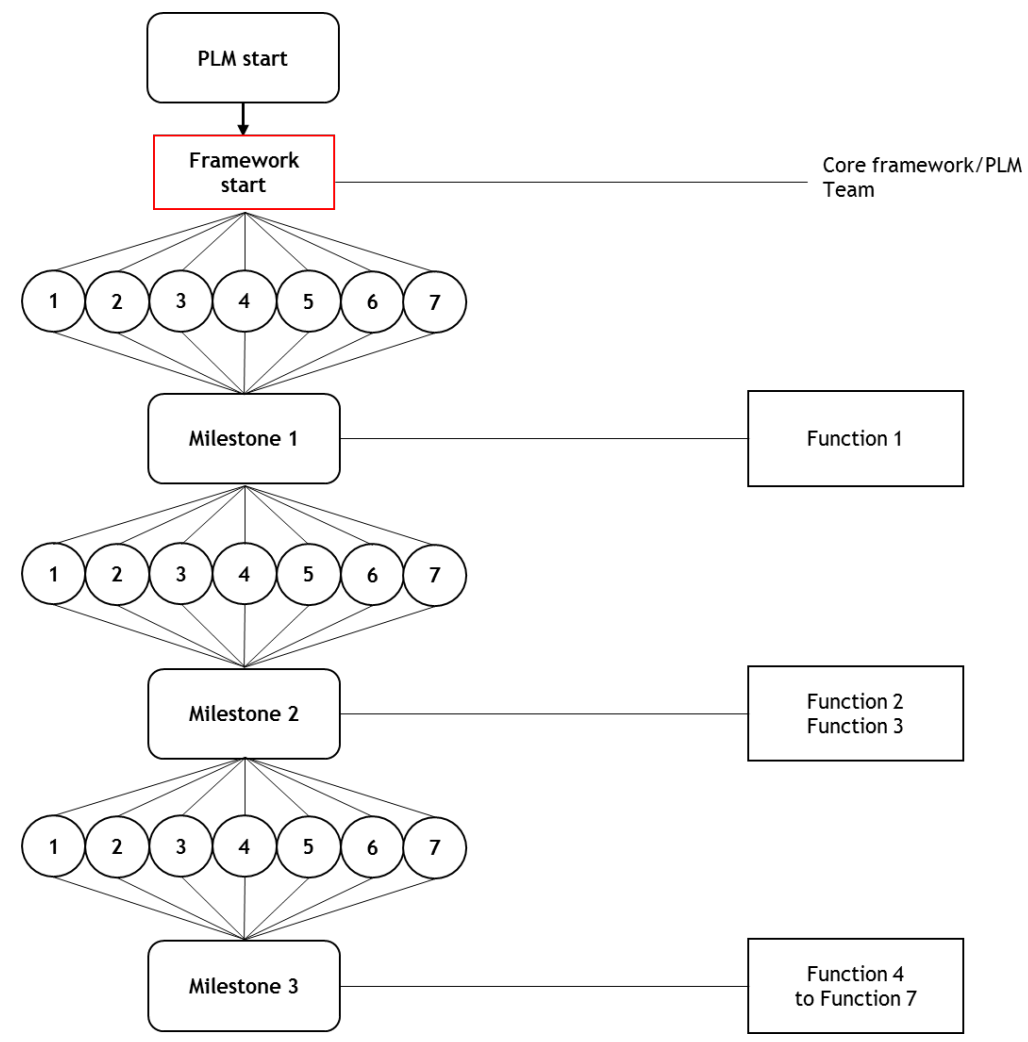

Figure 6: Execution strategy of the integrated value proposition design framework 
At each milestone the project leader determines which functional tasks should be completed for the next stage within the overall project. The project leader should also guide the representatives of the multifunctional teams to make integrated decisions and time-oriented deliverables.

\subsection{Framework methods and tools}

After the ideal set of value propositions for the product has been determined along with the value creating functional tasks, the value propositions are used as input to estimate the lifetime uptake model and the financial model for the product. From this information, a stochastic simulation model is created in the programming language $R$ (CRAN R software, $R$ language reference, version 3.1, available at http://cran.r-project.org/) to conduct what-if scenario analysis, which measures the product's key performance indicators.

In Step 1 of the simulation model, the uptake of the value proposition is modelled using the Generalised Bass model [5]. Using the Monte Carlo simulation, this uptake is modelled through the value proposition lifetime, calculating the most probable sales numbers of the proposition as it diffuses across the different segments of the customer target market. The model parameters are estimations from similar products launched in the industry under investigation, by using a nonlinear least squares estimation of existing sales numbers. Figure 7 shows an example of the forecasted sales figures as simulated through the model.

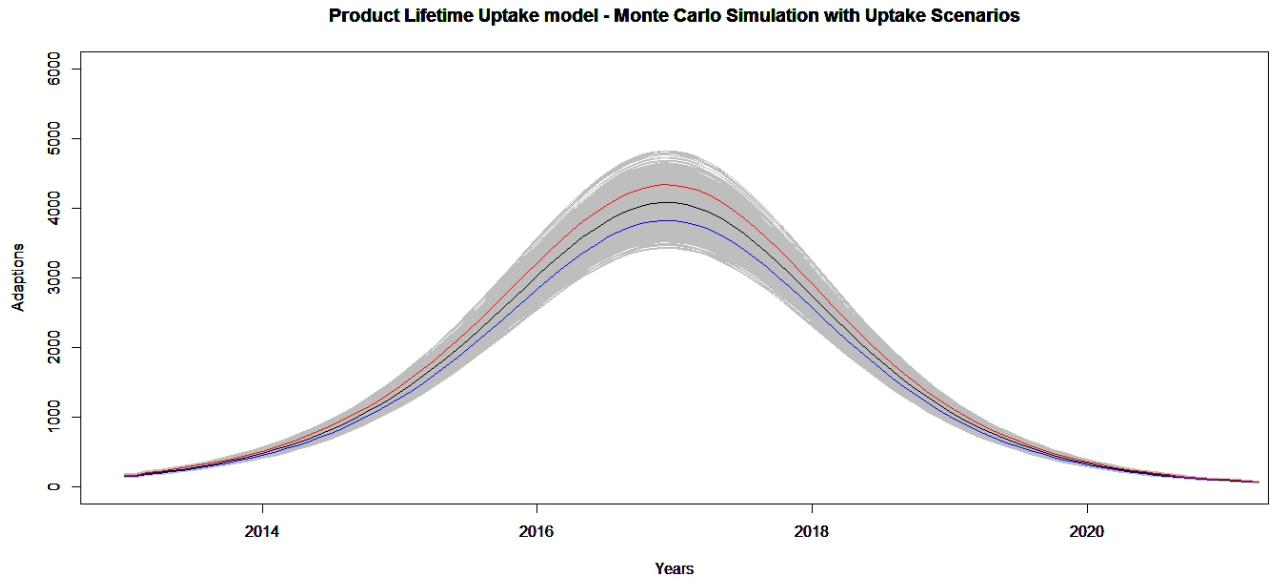

Figure 7: Product lifetime uptake model

Using a Generalised Bass model, the PLM team can model the impact of advertising campaigns and price elasticity models during the assessment of the lifetime uptake of the value proposition, as depicted in Figures 8.

In Step 2 of the model, the customer lifetime value is predicted as the net profit worth of the customer. This entails using the CLV per customer (Equation 1) and combining it with the product uptake model. Key inputs to this model are the customer target segment and value band information, which will generate the estimated aggregated profit income for the value proposition across time, as depicted in Figure 9.

The framework is not intended as a recipe for success; it is intended that organisations adopt the principles as good design principles that will make the PLM more efficient and effective. Following a process that is based on good system engineering practices will allow the organisation to deal effectively with any value proposition scale and complexity, while the methods applied ensure that good planning and communication practices can be followed. 
Generalised Bass model - incorporating Price Elasticity and Advertising Spend

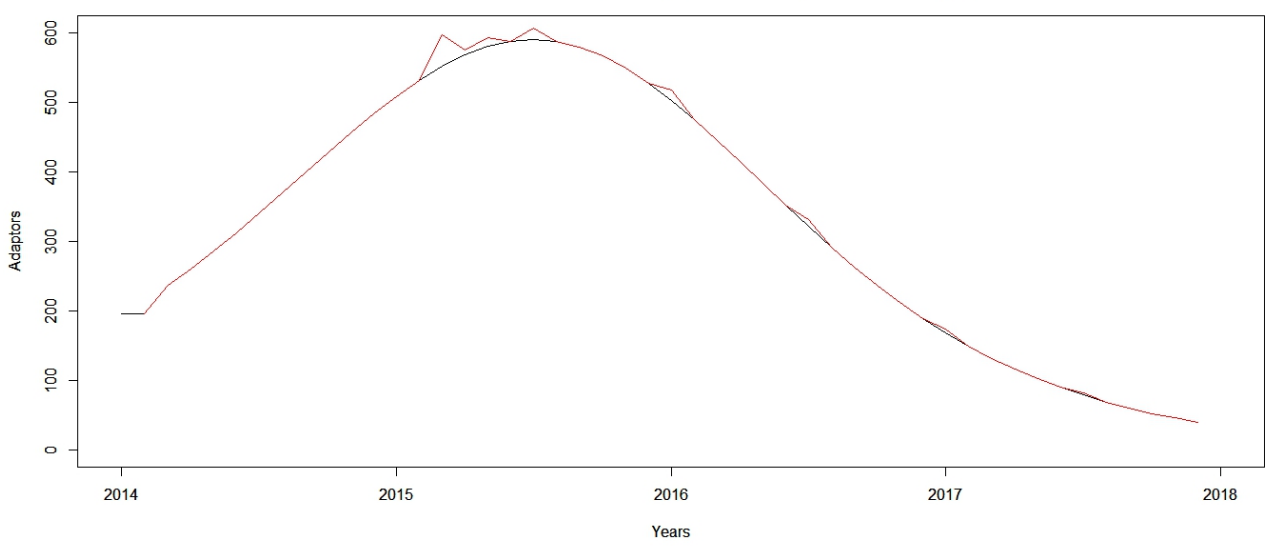

Figure 8: The influence of price promotion on the uptake of a product

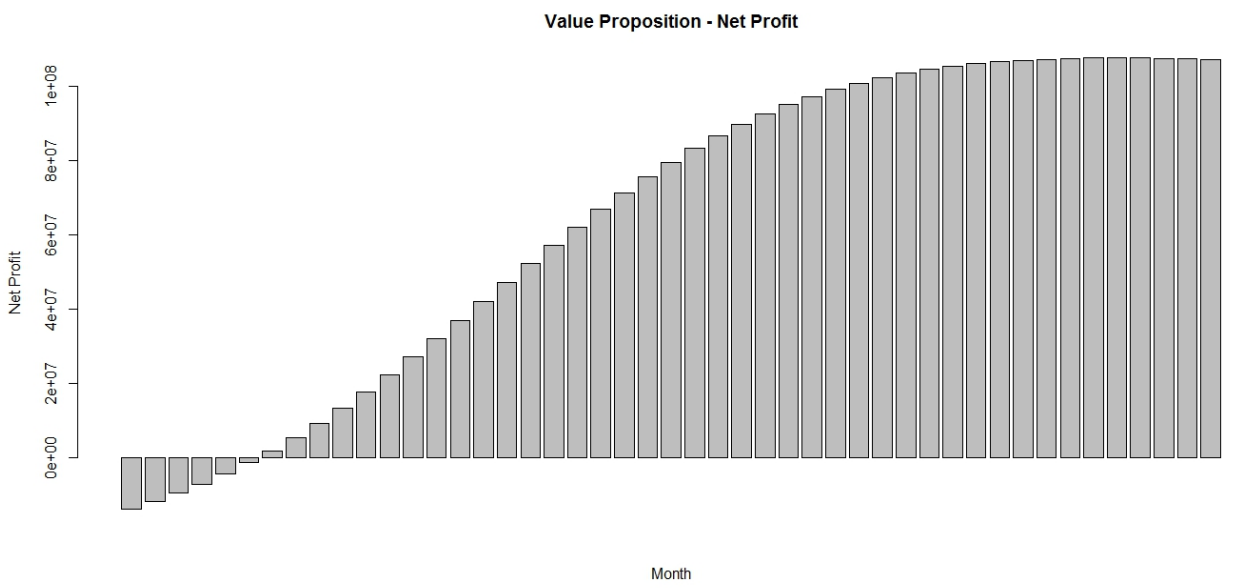

Figure 9: Product financial model

\section{CONCLUSION}

The integrated value proposition design framework presented in this paper differs from traditional PLM approaches because a customer-centric view is followed from start to end during the process. The voice of the customer is captured at the start of the process through the Refined Kano model, and translated at every process step by means of the QDF matrix.

The Blue Ocean strategy integrates the bottom-up process from the customer's viewpoint with the top-down view from a marketing strategy and financial objectives perspective.

The ability to integrate the customer perceived quality value proposition attributes with the organisation's financial and marketing objectives provides a powerful design instrument through which all stakeholders in the process are aligned around common objectives. Using a quantitative simulation model to simulate the assumptions of the organisation provides a quantitative tool to integrate marketing, sales, operations, and finances. Traditionally, business case numbers are compiled and assessed by the finance team as a separate work stream. In the proposed framework, however, numbers from marketing, sales, operations, 
and finances are integrated and used as a communication message from the first milestone to the last, significantly reducing any process re-work needed to try and fit design with financial revenue and profit targets.

Quantitative models alone will not ensure success, but in this framework we have identified two critical success factors as key to the execution of the framework: the first is systems engineering principles as they are realised in project management through functional decomposition and parallelisation of work activities; and the second is leadership through effective team structures.

The combination of structure, process, and people in the PLM process through this framework provides tangible actions in which the competitive edge of the organisation can be addressed by reducing the time-to-market with new products and services, while increasing product and service quality as experienced by the customer. In addition, this framework provides strategic and tactical benefits from a management perspective. In the tactical sense it is a planning and communication tool for large multifunctional teams; and in the strategic sense, it is a what-if scenario tool to test realistic marketing strategies and financial objectives throughout the organisation's value chain.

\section{REFERENCES}

[1] Ameri, F. \& Dutta, D. 2005. Product lifecycle management: Closing the knowledge loops. Computer-Aided Design \& Applications, 2(5), pp. 577-590.

[2] Anderson, J., Narus, J. \& van Rossum, W. 2006. Customer value propositions in business markets. Harvard Business Review, March, pp. 1-10.

[3] Ballard, K. 2008. Building a strong customer-centric strategy to enable CRM and develop customer loyalty. Master of Science thesis: University of Oregon.

[4] Barns, C., Blake, H. \& Pinder, D. 2009. Creating and delivering your value proposition: Managing customer experience for profit. USA: Kogan Page Limited

[5] Bass, F., Krishnan, T. \& Jain, D. 1994. Why the Bass Model fits without decision variables. Marketing Science, 13(3), pp. 203-222.

[6] Bass, F. 1969. A new product growth model for consumer durables. Management Science, 15(5), pp. 215-227.

[7] Bolton, R., Gustafsson, A., McColl-Kennedy, J., Sirianni, N. \& Tse, D. 2014. Small details that make big differences: A radical approach to consumption experience as a firm's differentiating strategy. Journal of Service Management, 25(2), pp. 253-274

[8] Clatworthy, S. 2011. Service innovation through touch-points: Development of an innovation toolkit for the first stages of new service development. International Journal of Design, 5, (2), pp. 15-28.

[9] Corallo, A., Latino, M., Lazoi, M., Lettera, S., Marra, M. \& Verardi, S. 2013. Defining product lifecycle management: A journey across features, definitions, and concepts. ISRN Industrial Engineering 2013, 2013(2013), pp.1-10.

[10] Epetimehin, F.M. 2011. Market segmentation: A tool for improving customer satisfaction and retention in insurance service delivery. Journal of Emerging Trends in Economics and Management Sciences, 2(1), pp. 62-67.

[11] Gecevska, V., Chiabert, P., Anisic, Z., Lombardi, F. \& Cus, F. 2010. Product lifecycle management through innovative and competitive business environment. Journal of Industrial Engineering and Management, 3(2), pp. 323-336.

[12] Gupta, S., Hanssens, D., Hardie, B., Kahn, W., Kumar, V., Lin, N., Ravishanker, N., \& Sriram, S. 2006. Modelling customer lifetime value. Journal of Service Research, 9(2), pp. 139-155.

[13] Gupta, S. \& Lehman, R. 2005. Managing customers as investments. Executive Book Summaries. 28(1), pp. 1-8.

[14] Hauser, J. \& Clausing, D. 1988. The house of quality. Harvard Business Review, May-June, pp. 113.

[15] Johnston, R. \& Kong, X. 2011. The customer experience: A road-map for improvement. Managing Service Quality. 21(1), pp. 5-24.

[16] Kessler, E., Bierly, P. \& Gopalakrishnan, S. 2001. Vasa syndrome: Insights from a 17th-century new-product disaster. Academy of Management Executive, 15(3), pp. 80-91.

[17] Kim, C. \& Mauborgne, R. 2004. Blue ocean strategy. Harvard Business Review, October, pp. 110.

[18] Lee, S. 2009. Building an effective total customer experience model for telecom operators. Customer Think. Retrieved from http://customerthink.com/telecom_total_customer_ experience_model/. Accessed on 22 July 2014. 
[19] Metropolis, N. \& Ulam, S. 1949. The Monte Carlo method. Journal of the American Statistical Association, 44(247), pp. 335-341.

[20] Rashid, M. 2010. A review of state-of-art on Kano model for research direction. International Journal of Engineering Science and Technology, 2(12), pp. 7481-7490.

[21] Sheth, J., Sisodia, R. \& Sharma, R. 2000. The antecedents and consequences of customercentric marketing. Journal of the Academy of Marketing Science, 28(1), pp. 55-66.

[22] Straub, R. \& Kirby, J. 2014. Better management could spur a new era of economic growth. Harvard Business Review Blog Network. Retrieved from http://blogs.hbr.org/2014/05/bettermanagement-could-spur-a-new-era-of-economic-growth/. Accessed on 16 May 2014.

[23] Osterwalder, A. 2012. Achieve product market fit with our brand new value proposition designer canvas. Business Model Alchemists. Retrieved from http: / / businessmodelalchemist.com/blog/2012/08/achieve-product-market-fit-with-our-brandnew-value-proposition-designer.html. Accessed on 10 July 2014.

[24] Van de Ven, A.H. 1986. Central problems in the management of innovation. Management Science, 32(5). pp. 590-607.

[25] Yang, C. \& Sung, D. 2011. An integrated model of value creation based on the refined Kano's model and the Blue Ocean strategy. Total Quality Management \& Business Excellence, 22(9), pp. 925-940.

[26] Yang, C. 2005. The Refined Kano's model and its application. Total Quality Management, 16(10), pp. 1127-1137.

[27] Zeng, Y. \& Liu, W. 2009. Product lifecycle management: A review. Proceedings of the ASME 2009 International Design Engineering Technical Conferences \& Computers and Information in Engineering Conference. San Diego, USA: IDETC/CIE, pp. 1-13. 